\title{
William Maxwell Cowan 1931-2002
}

T met William Maxwell Cowan over 30 years 1 ago when I was a young post-doc working at Oxford University. I and many others knew him to be a skilled neurobiologist, but it is perhaps as the Vice President and Chief Scientific Officer of the Howard Hughes Medical Institute in Bethesda, Maryland, that he will be best remembered by the biomedical research community. There could not, I believe, have been a more successful union of man and job.

Born in Johannesburg, Max completed his first degree at the University of the Witwatersrand and moved to Oxford University where he enjoyed a productive period from 1953 to 1966, gaining, en passant, both his D.Phil. and B.M./B.Ch. degrees. Together with Thomas P.S. Powell, he studied connections of the hippocampus, thalamus and basal ganglia and produced some of the most important papers in modern neuroanatomy. Max was a first-class developmental neurobiologist who made important contributions to the investigation of regressive events in brain development, and a continuing stream of meticulous neuroanatomical studies characterized the output of his laboratory.

Some of those who knew Max as a Fellow of Pembroke College and Lecturer at Balliol undoubtedly saw him as one destined for a lifetime career in that milieu. But to others, there were already clear signs of the leadership skills and capacity to influence opinion that made him so well equipped to direct the research expenditure of the Hughes Institute.

A sabbatical year at Washington University in St. Louis convinced him that he would find greater opportunities in the United States and he returned to become Chair of the Department of Anatomy and Neurobiology at Washington University in 1968. He rejuvenated a department that had seen better days, transforming it into one of the first modern departments of neuroscience. He was part of a group headed by P. Roy Vagelos that created the first truly interdisciplinary graduate programs in the biomedical sciences-programs that transcended the traditional barriers between departments and schools and that are now widely emulated. Max succeeded Vagelos as Director of the Division of Biological and Biomedical Sciences.

It was while he was Vice President of the Salk Institute between 1980 and 1986 that Max's national and international reputation grew. Honors came his way, and he became increasingly involved in the promotion and management of scientific research and with the federal and private agencies that funded it. A skill for reviewing and report-writing with a ready and lucid pen-and a voice that could always be relied upon to give an articulate and considered judgment-ensured that he was much in demand. These talents made him highly effective in helping establish and secure the continuity of organizations such as the Neurosciences Research Program and the Dana Alliance for Brain Initiatives as they struggled for support in their early years. His effectiveness as a spokesperson for neuroscience gained him successive appointments as Editor of the Journal of Comparative Neurology, Journal of
Neuroscience and Annual Review of Neuroscience, as well as election as the eighth President of the Society for Neuroscience.

Max had the remarkable ability to rapidly build up a strong knowledge base about fields other than his own, and this served him well in building a reputation among non-neuroscientists and administrators alike. It was these attributes that made him a natural choice for the position of Chief Scientific Officer of the Howard Hughes Institute for Medical Research in 1987, after its leadership had changed and when it was set to embark upon a much-expanded program of support for biomedical research. I think that a brief intervening period as Provost and Executive Vice Chancellor of Washington University must have been remarkably dull for a man of Max's interests and abilities.

The Hughes Institute had traditionally supported the fields of molecular biology and genetics, but Max took on the task of expansion into additional areas of scientific research. He was in his element choosing new areas worthy of funding and identifying new investigators of great promise, and the man and the mission became virtually synonymous. With an ever watchful eye towards advances in technology and new intellectual approaches, a keen sense for talent in all fields, he guided the Hughes Institute into supporting programs in cell biology, immunology, structural biology, epidemiology, biostatistics and neuroscience. Later in life, he recognized that cognitive neuroscience had taken on new life, mainly as the result of improvements in functional brainimaging techniques, and he directed resources towards investigators studying brain function at this level-a move into systems biology that would hitherto not have been thought of as an abiding interest of the Hughes Institute.

He also introduced some degree of accountability among Hughes Investigators whose appointments had not been made by transparent means, and who enjoyed enormous sinecure. Max helped introduce the forms of scientific accountability practiced in academic institutions, democratized the Institute by giving Investigators' representatives a voice in its affairs and gave universities the right to nominate scientists for Investigatorships. He also insisted that Hughes Investigators compete for fading from the National Institutes of Health-placing them in the same competitive situation as other scientists-and did not shrink from closing down labs that had become non-productive.

Few people in biology have ever commanded such enormous resources as Max Cowan. In 2001, the Hughes Institute disbursed some $\$ 515$ million in funds for medical research alone. He used the funding wisely and well to enhance the mission of the Hughes Institute and to advance medical research in ways that could not have been envisaged when he was a neuroanatomist at Oxford.

EDWARD G. JONES Center for Neuroscience University of California, Davis Davis, California, USA 